\title{
钯催化[4+1+1]环加成反应直接合成 $N$-取代喹唑啉-2,4(1H,3H)-二酮
}

\author{
丁永正黄汉民*
}

(中国科学技术大学化学与材料科学学院 合肥微尺度物质科学国家研究中心 合肥 230026)

\section{Palladium-Catalyzed [4+1+1] Cycloaddition for the Direct Synthesis of $N$-Substituted Quinazoline-2,4(1H,3H)-diones}

\author{
Ding, Yongzheng Huang, Hanmin* \\ (Hefei National Laboratory for Physical Sciences at the Microscale and Department of Chemistry, \\ University of Science and Technology of China, Hefei, 230026)
}

喹唑啉二酮类化合物是一类重要的杂环化合物, 其 中 $N^{3}$-取代和 $N^{1}, N^{3}$-二取代的喹唑啉-2,4-( $(1 H, 3 H)$-二酮衍 生物具有广泛的药理和生物活性, 如抗癌、抗病毒、抗 菌、除草等作用, 在医药和农药领域具有重要的应用价 值 ${ }^{[1]}$. 因此, 发展其高效的合成方法具有非常重要的意 义. 目前, 多种合成策略已相继被化学家们开发出来. 其中，直接利用 $N$-烷基取代的邻氨基苯甲酸类化合物 作为起始原料这一策略备受关注. 主要包括(1)靛红酸 䣶与芳基异氧酸酯反应 ${ }^{[2]}$, (2)邻氨基苯甲酰胺环化羰基 化 ${ }^{[3]}$ ，(3)邻氨基苯甲酸酯与芳基异㲵酸酯加成/环化 ${ }^{[4]}$, (4)邻氨基苯甲酸酯经烷氧羰基化、氨解、环化合成 $N$ 取代喹唑啉二酮衍生物等方法 ${ }^{[5]}$. 尽管该类化合物的合 成取得了长足的发展, 但这些方法在一定程度上存在着 诸多缺点, 如需要利用复杂、昂贵、不易得甚至高毒的 试剂作为原料; 反应条件苛刻, 需要高温或高压; 反应 步骤多, 时间长, 原子经济性和步骤经济性低.

基于钯催化羰基化反应是一种高效的构建杂环化 合物的方法 ${ }^{[6-8]}$, 为了解决上述问题, 近期, 河南师范大 学化学化工学院张贵生课题组将催化羰基化与串联反 应结合, 利用 $N$-取代邻氨基苯甲酸、胺、一氧化碳为原 料, 通过钯催化 $[4+1+1]$ 串联环加成反应一步高效合 成了 $N$-取代喹唑啉-2,4-( $1 H, 3 H)$-二酮类化合物(Scheme $1)^{[9]}$.

该反应条件温和, 只需 $101 \mathrm{kPa}$ 压力的一氧化碳, 在 $60{ }^{\circ} \mathrm{C}$ 一步即可较高的收率得到相应的产物. 该反应 的底物简单易得, 底物范围较广, 对于脂肪胺、多种芳 香胺和取代的邻氨基苯甲酸都具有较好的兼容性. 另

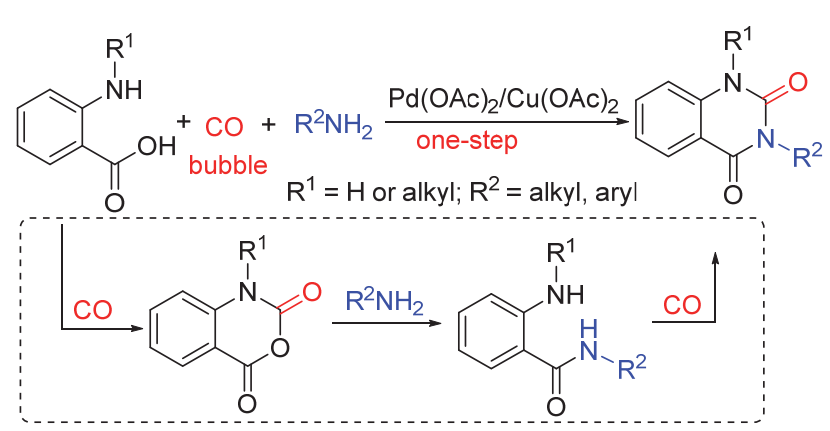

图式 1 钯催化 $[4+1+1]$ 串联环加成一步合成 $N$-取代喹唑啉2,4-(1H,3H)-二酮衍生物

Scheme1 Pd(II)-catalyzed $[4+1+1]$ cascade cycloaddition for the synthesis of $N$-substituted quinazoline-2,4-(1H,3H)-dione derivatives

外，利用廉价易得的邻氨基苯甲酸和相应的胺为原料, 能以 $47 \%$ 的收率一步合成药物 Pelanserin, 展现了该方 法在药物合成中的实用性(Scheme 2).

为了更好地理解该反应机理，作者合成了多种可能 的反应中间体并进行探究(Scheme 3). 首先在标准条件 下，作者将邻甲氨基苯甲酸与一氧化碳反应，以 $83 \%$ 的 收率得到 $N$-甲基靛红酸䣶. 该中间体在 $60{ }^{\circ} \mathrm{C}$ 下与胺反 应, 需 $5 \mathrm{~min}$ 便几乎完全转化为 $N$-甲基苯甲酰胺. 此中 间体在标准条件下反应 $10 \mathrm{~h}$ 便能以 $90 \%$ 的收率生成目 标产物. 这些结果表明该反应经历了羰基化环化/开环/ 羰基化环化一系列过程.

综上, 张贵生课题组开发了一种以邻氨基苯甲酸、 胺和一氧化碳为原料, 一步制备 $N^{3}$-取代和 $N^{1}, N^{3}$-二取 代的喹唑啉-2,4-(1H,3H)-二酮衍生物的高效方法. 该方

* Corresponding author. E-mail: hanmin@ustc.edu.cn. Published online April 1, 2021. 


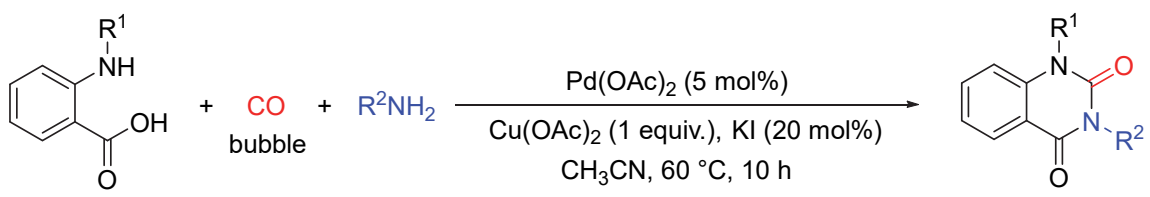<smiles>O=C(Cn1c(=O)[nH]c2ccccc2c1=O)c1ccccc1</smiles>

$80 \%$<smiles>CC(C)Cn1c(=O)c2ccccc2n(C)c1=O</smiles>

$86 \%$<smiles>CC(C)n1c(=O)n(C(=O)c2ccccc2)c(=O)c2ccccc21</smiles>

$80 \%$<smiles>Cn1c(=O)n(C2CCCCC2)c(=O)c2ccccc21</smiles>

$74 \%$<smiles>COc1ccc2c(c1)c(=O)n(Cc1ccccc1)c(=O)n2C</smiles>

$75 \%$<smiles>Cn1c(=O)n(-c2ccc(Br)cc2)c(=O)c2ccccc21</smiles>

$78 \%$<smiles>CC(C)Cn1c(=O)c2ccc(Cl)cc2n(C)c1=O</smiles>

$86 \%$<smiles>Cn1c(=O)n(-c2cccc3ccccc23)c(=O)c2ccccc21</smiles>

$73 \%$<smiles>Cn1c(=O)c2ccccc2n(C)c1=O</smiles>

$84 \%$<smiles></smiles>

$33 \%$

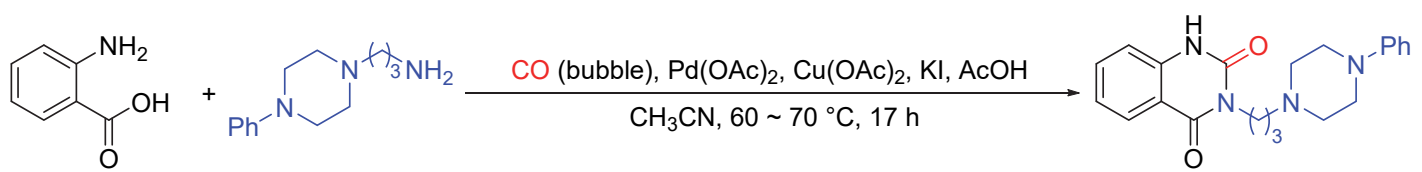

Pelanserin, $47 \%$ yield

图式 2 底物范围考察及合成应用

Scheme 2 Representative substrates scope and synthesis application

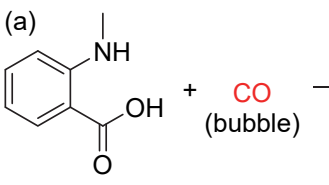

(b)<smiles>Cn1c(=O)oc(=O)c2ccccc21</smiles>

$\mathrm{CH}_{3} \mathrm{CN}, 60^{\circ} \mathrm{C}, 5 \mathrm{~min}$

(c)<smiles>CNc1ccccc1C(=O)N[13C](=O)[O-]</smiles>

$\mathrm{Pd}(\mathrm{OAc})_{2}(5 \mathrm{~mol} \%)$ $\mathrm{Cu}(\mathrm{OAc})_{2}$ (2 equiv.) $\mathrm{CH}_{3} \mathrm{CN}, 60^{\circ} \mathrm{C}, 10 \mathrm{~h}$ yield $83 \%$<smiles>CNc1ccccc1C(=O)NC(=O)OCc1ccccc1</smiles><smiles>CC(C)Cn1c(=O)c2ccccc2n(C)c1=O</smiles>
yield $90 \%$

图式 3 控制反应

Scheme 3 Control experiments

法原料简单、便宜、易得，反应条件温和，无需高温高 压, 具有很高的原子经济性和步骤经济性, 为快速制备
多样化的 $N^{3}$-取代和 $N^{1}, N^{3}$-二取代的喹唑啉-2,4-(1H,3H)二酮衍生物提供了一种高效、简洁、绿色的合成方法，在 药物的合成中具有比较重要的实用价值.

\section{References}

[1] Khan, I.; Ibrar, A.; Abbas, N.; Saeed, A. Eur. J. Med. Chem. 2014, 76,193

[2] Beutner, G. L.; Hsiao, Y.; Razler, T.; Simmons, E. M.; Wertjes, W. Org. Lett. 2017, 19, 1052.

[3] Kirincich, S. J.; Xiang, J.; Green, N.; Tam, S.; Yang, H. Y.; Shim, J.; Shen, M. W. H.; Clark, J. D.; McKew, J. C. Bioorg. Med. Chem. 2009, 17, 4383.

[4] Buckman, B. O.; Mohan, R. Tetrahedron Lett. 1996, 37, 4439.

[5] Fehrentz, J. A.; Winternitz, F.; Martinez, J. Tetrahedron Lett. 1996 37, 7031.

[6] Hu, Y.; Shen, Z.; Huang, H. ACS Catal. 2016, 6, 6785.

[7] Yu, H.; Zhang, G.; Huang, H. Angew. Chem., Int. Ed. 2015, 54, 10912

[8] Wu, X.-F.; Neumann, H.; Beller, M. Chem. Rev. 2013, 113, 1.

[9] Zhang, X.; Ding, Q.; Wang, J.; Yang, J.; Fan, X.; Zhang, G. Green Chem. 2021, 23, 526 